\title{
Da atuação das forças armadas na segurança pública dos estados-membros
}

\author{
Performance of the armed forces in the public security of the member-states
}

\author{
Marília do Amaral Felizardo ${ }^{1}$ \\ Vilma Aparecida do Amaral ${ }^{2}$
}

\begin{abstract}
Resumo
0 presente trabalho científico tem por objetivo demonstrar as conseqüências da reiterada atuação das Forças Armadas na Segurança Pública dos Estados-membros e apresentar propostas para uma possível solução das problemáticas enfrentadas. "Ab initio" são apontados o fundamento legal para a intervenção das Forças Armadas na Segurança Pública dos Estados-membros, as hipóteses legais de ocorrência, bem como as conseqüências da reiterada atuação. Perante esses estudos pôde-se observar quais são as falhas específicas em cada uma das instituições da Segurança Pública e das Forças Armadas e cogitar metas para melhorá-las e assegurar a eficácia da segurança. Dito isto, tira-se como conclusão que a atuação reiterada das Forças Armadas na Segurança Pública dos Estados-membros é inconstitucional, já que esse é um ato que deve ser adotado em caráter excepcional, com fundamento no art.142 da Constituição Federal, de modo a garantir a lei e a ordem na sociedade e evitar situtações de caos.
\end{abstract}

Palavras Chave: Segurança Pública; Forças Armadas; Intervenção.

\begin{abstract}
The present scientific work aims to demonstrate the consequences of repeated performance of the Armed Forces in Public Security of Member-States and it also aims to make proposals for a possible solution of the problems faced. "Ab initio" the legal basis for the intervention of the Armed Forces in Public Security of MemberStates, the legal hypothesis of occurrence and the consequences of repeated performance are pointed out. In front of these studies it could be observed what are the specific flaws in each of the institutions of Public Security and Armed Forces and it could be contemplated goals to improve these institutions and ensure effective security. That said, take it as a conclusion that the repeated performance of the Armed Forces in Public Security of M ember-States is unconstitutional, since this is an act that should be adopted on an exceptional basis of art.142 of the Constitution, ensuring law and order in society and avoiding chaos situations.
\end{abstract}

Keywords: Public Security; Armed Forces; Intervention.

\footnotetext{
${ }^{1}$ Graduanda do 50 ano da Universidade Estadual de Londrina.

${ }^{2}$ Mestra docente da Universidade Estadual de Londrina.
} 


\section{Introdução}

Em meados de 2008, três jovens do morro da Providência (centro do Rio de Janeiro) foram torturados e mortos depois de supostamente serem levados a traficantes do morro da M ineira, por militares do Exército que ocupavam o morro para a feitura de obras.

Tal notícia fez despertar sobre a legalidade da ocupação do Exército no morro, o que motivou desbravar o tema da "atuação das Forças Armadas na Segurança Pública dos Estados-membros", que demonstra grande relevância frente a preocupante opinião e ação de políticos que defendem a reiterada ação das Forças Armadas nos Estados-membros.

Por método dedutivo, partindo da segurança genérica como direito fundamental individual e segurança pública como direito fundamental social de dever estatal, restringe-se o tema à fase em que se albergam as hipóteses de atuação das Forças Armadas na Segurança Pública dos Estados-membros e as conseqüências de intervenções reiteradas.

No decorrer da pesquisa, não foram encontradas dificuldades na coleta de materiais, o que privilegiou o desencadeamento do presente trabalho, que por seu turno, vislumbra analisar a atuação das Forças Armadas na Segurança Pública e os momentos oportunos desta intromissão, que são extremamente restritos, já que o capítulo que versa sobre o tema (art.144, CF) não faz referência às Forças Armadas, que por sua vez são tratadas em capítulo próprio (art.142, CF).

A atuação das Forças Armadas na Segurança Pública dos Estados-membros é pautada no art.142 da CF, ao tratar da garantia da lei e da ordem, de modo a configurar a regra da não intromissão, com excepcionais permissivos legais, dispostos nas hipóteses de: a) Intervenção Federal; b) Estado de Defesa; c) Estado de Sítio; d) Segurança em eventos oficiais ou públicos, de relevância nacional, particularmente os que contém a participação de Chefes de Estado ou de Governo estrangeiro; e) Policiamento ostensivo e de choque, por solicitação de Governador de Estado; f) Realização de diligências determinadas em inquérito militar.

Dito isto, traçam-se as consequêencias da não observância do texto constitucional, quando da reiterada atuação das Forças Armadas na Segurança Pública dos Estadosmembros, como: o enfraquecimento do Estado democrático de direito; a desarmonia dos três poderes; o desequilíbrio do pacto federativo; a instauração do Estado de caos; 0 esfacelamento dos direitos fundamentais; e a diminuição da atuação dos órgãos da 
Segurança Pública encarregados de prover a segurança dos Estados-membros. Diante desses problemas são estabelecidas propostas para solucioná-los.

\section{Da atuação das forças armadas na segurança pública dos estados-membros}

Diante de tudo o que já foi exposto, denota-se que o texto constitucional, no seu Título V, denominado Da Defesa do Estado e das Instituições Democráticas, dedicou um capítulo inteiro ao tema Da Segurança Pública, que se concentra em um único dispositivo: artigo 144, com seus respectivos incisos e parágrafos. De sua leitura se identifica o conjunto de órgãos aos quais o constituinte encarregou a preservação da ordem pública e da incolumidade das pessoas e do patrimônio: Polícia Federal, Polícia Rodoviária e Ferroviária Federal, Polícia Civil, Polícia Militar, Corpo de Bombeiros Militar, não fazendo menção em momento algum no decorrer do capítulo às Forças Armadas, que são tratadas em capítulo específico dentro do mesmo título.

Diante da omissão constitucional das Forças Armadas como órgão pertencente à Segurança Pública, resta por evidente que aquelas não podem atuar em questões de Segurança Pública, sendo esse um papel dos órgãos a esta correspondentes (NOBRE, 2007).

A despeito disso, as Forças Armadas têm participado de diversas ações na área da Segurança Pública, em diversos Estados da Federação, apesar de não ser citada como órgão de atuação do referido instituto, haja vista que compõe instituto diverso; pois como visto em momento oportuno, a Segurança Pública se foca ao ambiente interno, enquanto as Forças Armadas é voltada ao meio externo a fim de assegurar a ordem no país.

O fundamento da atuação das Forças Armadas na Segurança Pública se pauta no art.142 da Constituição Federal, que trata da garantia da lei e da ordem. Assim, a regra é que as Forças Armadas não se intrometam em questões de Segurança Pública, podendo fazê-lo em especialíssimas situações, como doravante se observará.

Sobre o tema, vale a pena conferir o enunciado do art. 15 da Lei Complementar 97/99, que trata das "normas gerais para a organização, preparo e emprego das Forças Armadas": 
Art. 15.0 emprego das Forças Armadas na defesa da Pátria e na garantia dos poderes constitucionais, da lei e da ordem, e na participação em operações de paz, é de responsabilidade do Presidente da República, que determinará ao Ministro de Estado da Defesa a ativação de órgãos operacionais, observada a seguinte forma de subordinação:

[...]

§ 10Compete ao Presidente da República a decisão do emprego das Forças Armadas, por iniciativa própria ou em atendimento a pedido manifestado pelo Estado por quaisquer dos poderes constitucionais, por intermédio dos Presidentes do Supremo Tribunal Federal, do Senado Federal ou da Câmara dos Deputados.

$\S 20$ A atuação das Forças Armadas, na garantia da lei e da ordem, por iniciativa de quaisquer dos poderes constitucionais, ocorrerá de acordo com as diretrizes baixadas em ato do Presidente da República, após esgotados os instrumentos destinados à preservação da ordem pública e da incolumidade das pessoas e do patrimônio, relacionados no art. 144 da Constituição Federal. (grifo nosso)

$\S 30$ Consideram-se esgotados os instrumentos relacionados no art. 144 da Constituição Federal quando, em determinado momento, forem eles formalmente reconhecidos pelo respectivo Chefe do Poder Executivo Federal ou Estadual como indisponíveis, inexistentes ou insuficientes ao desempenho regular de sua missão constitucional. (grifo nosso) (Incluído pela Lei Complementar no 117, de 2004)

$\S 40 \mathrm{Na}$ hipótese de emprego nas condições previstas no § 3odeste artigo, após mensagem do Presidente da República, serão ativados os órgãos operacionais das Forças Armadas, que desenvolverão, de forma episódica, em área previamente estabelecida e por tempo limitado, as ações de caráter preventivo e repressivo necessárias para assegurar o resultado das operações na garantia da lei e da ordem. (Incluído pela Lei Complementar no 117, de 2004)

$\S 50$ Determinado o emprego das Forças Armadas na garantia da lei e da ordem, caberá à autoridade competente, mediante ato formal, transferir o controle operacional dos órgãos de Segurança Pública necessários ao desenvolvimento das ações para a autoridade encarregada das operações, a qual deverá constituir um centro de coordenação de operações, composto por representantes dos órgãos públicos sob seu controle operacional ou com interesses afins. (Incluído pela Lei Complementar no 117, de 2004)

$\S 60$ Considera-se controle operacional, para fins de aplicação desta Lei Complementar, o poder conferido à autoridade encarregada das operações, para atribuir e coordenar missões ou tarefas específicas a serem desempenhadas por efetivos dos órgãos de Segurança Pública, obedecidas as suas competências constitucionais ou legais. (Incluído pela Lei Complementar no 117, de 2004)

$\S 700$ emprego e o preparo das Forças Armadas na garantia da lei e da ordem são considerados atividade militar para fins de aplicação do art. 9o, inciso II, alínea C, do Decreto-Lei no 1.001, de 21 de outubro de 1969 - Código Penal Militar. (Incluído pela Lei Complementar no 117, de 2004).

Quanto à conceituação do termo "garantia da lei e da ordem", o Decreto 3.897/2001 positiva da seguinte maneira: 
Art. 3ํ Na hipótese de emprego das Forças Armadas para a garantia da lei e da ordem, objetivando a preservação da ordem pública e da incolumidade das pessoas e do patrimônio, porque esgotados os instrumentos a isso previstos no art. 144 da Constituição, Ihes incumbirá, sempre que se faça necessário, desenvolver as ações de polícia ostensiva, como as demais, de natureza preventiva ou repressiva, que se incluem na competência, constitucional e legal, das Polícias Militares, observados os termos e limites impostos, a estas últimas, pelo ordenamento jurídico.

Parágrafo único. Consideram-se esgotados os meios previstos no art. 144 da Constituição, inclusive no que concerne às Polícias Militares, quando, em determinado momento, indisponíveis, inexistentes, ou insuficientes ao desempenho regular de sua missão constitucional. (grifo nosso)

Com o fim de definir de maneira taxativa e resumir os dispositivos acima transcritos, o glossário das Forças Armadas apresenta a seguinte definição:

Atuação coordenada das Forças Armadas e dos Órgãos de Segurança Pública na garantia da lei e da ordem, por iniciativa de quaisquer dos poderes constitucionais, possui caráter excepcional, episódico e temporário. Ocorrerá de acordo com as diretrizes baixadas em ato do Presidente da República, após esgotados os instrumentos destinados à preservação da ordem pública e da incolumidade das pessoas e do patrimônio. A decisão presidencial para emprego das Forças Armadas nessa situação poderá ocorrer diretamente por sua própria iniciativa ou por solicitação dos chefes dos outros poderes constitucionais, representados pelos Presidentes do Supremo Tribunal Federal, do Senado Federal ou da Câmara dos Deputados (BRASIL, 2007).

Em síntese, é possível concluir que o termo "garantia da lei e da ordem" é utilizado para retratar situação extremada, ante ao quadro de verdadeira incapacidade ou insuficiência operacional dos órgãos de Segurança Pública para restabelecer a ordem das coisas, ou seja, quando houver verdadeiro colapso da Segurança Pública (NOBRE, 2007).

Apesar de sua atuação ser prevista constitucionalmente em momentos excepcionais, formadores de opinião lançam ao debate público propostas para uma atuação mais freqüente das Forças Armadas na Segurança Pública, o que é completamente inconstitucional, já que a redação constitucional e infraconstitucional é clara ao definir que a atuação das Forças Armadas na Segurança Pública dos Estados-membros se dará em momentos excepcionais, em hipóteses pré-determinadas (BARROSO, 2008). 


\section{Das hipóteses de atuação das forças armadas na segurança pública dos estados- membros}

As hipóteses de atuação válida das Forças Armadas na Segurança Pública dos Estados-membros, a fim de garantir a lei e a ordem, são: a) Intevenção Federal; b) Estado de defesa; c) Estado de sítio; d) Segurança em eventos oficiais ou públicos, de relevância nacional, particularmente os que contém a participação de Chefes de Estado ou de Governo estrangeiro; e) Policiamento ostensivo e de choque, por solicitação de governador de Estado-membro; f) Realização de diligências determinadas em inquérito militar (BARROSO, 2008).

Os três primeiros casos compreendem ações voltadas à preservação do equilíbrio federativo ou à defesa da ordem democrática e constituem limitações circunstanciais ao poder constituinte derivado (o que impede Emenda à Constituição durante sua vigência), já os três últimos contemplam situações menos drásticas do ponto de vista institucional, mas igualmente relevantes para a preservação da ordem pública e da incolumidade das pessoas e do patrimônio (BARROSO, 2008).

A Intervenção Federal, primeira hipótese de atuação das Forças Armadas na Segurança Pública, é o instituto que permite a interferência de um nível de poder sobre 0 outro. É de ocorrência excepcional, só é possível nos casos previstos taxativamente na Constituição, já que a regra geral é a da não-intervenção da União nos Estados.

A intervenção é "ato político que consiste na incursão da entidade interventora nos negócios da entidade que a suporta" (MIRANDA, 1970). É a antítese da autonomia, por ela afasta-se momentaneamente a atuação autônoma do Estado, Distrito Federal ou M unicípio que a tenha sofrido, já que a CF assegura a essas entidades a autonomia como princípio básico da forma federal de Estado adotada (SILVA, 2005, pp. 484-485).

Seus pressupostos de fundo são situações críticas que põem em risco a segurança do Estado, a ordem pública, o equilíbrio federativo, as finanças estaduais e a estabilidade da ordem constitucional (SILVA, 2005, p. 485).

No presente estudo, merece ênfase 0 inciso III do art.34, CF: “[...] pôr termo a grave comprometimento da ordem pública [...]", que deve ser inequívoco, concreto e objetivo. Sendo assim, o preceito constitucional se refere somente àquela situação em que o Estado- 
membro não possa superar. Sendo esse o caso, justificar-se-á a intervenção federal e a respectiva utilização das Forças Armadas, que atuarão no sentido de restabelecer a ordem.

Ao ser decretada a intervenção, o Governo Federal assumirá o controle dos órgãos estaduais de segurança, que atuarão sob as ordens do interventor (autoridade federal), em conjunto com as Forças Armadas. Se restringidas apenas determinadas áreas do território estadual, somente os órgãos policiais que atuam nelas passarão ao comando militar federal.

Para que isso se concretize, o Presidente deve apenas consultar o Conselho de Defesa Nacional, cuja opinião não vincula sua decisão.

Após a decretação da intervenção, 0 ato é submetido à apreciação do Congresso Nacional, no prazo de 24 horas (art.36, §1ํ, CF) (SILVA, 2005, p. 488). Como se trata de ato que implica a relativização da autonomia do Estado, o controle parlamentar é fundamental, para evitar que o Executivo federal pratique abusos.

A segunda hipótese é o Estado de defesa, que se consubstancia num conjunto ordenado de normas constitucionais que, informadas pelos princípios da necessidade e temporariedade, tem por objetivo permitir que se promova a manutenção ou o restabelecimento da normalidade constitucional, com menor sacrifício possível, de forma a preservar ou restabelecer, em locais restritos e determinados, a ordem pública e a paz social (SILVA, 2005, p. 763).

Assim sendo, uma vez que as Forças Armadas tenham logrado êxito no cumprimento desse objetivo, sua presença não tem mais justificativa, não podendo se prolongar no tempo para além do que o decreto prevê, haja vista que se trata de medida de legalidade excepcional, informada pelo princípio da necessidade. Somente diante da insuficiência dos meios normais de garantia da ordem pública se justifica a decretação do Estado de defesa.

Os fundamentos para a decretação do Estado de defesa são previstos pelo artigo $136{ }^{3}$ da Constituição e são: a) existência de grave e iminente instabilidade institucional que ameace a ordem pública ou a paz social ou; b) a manifestação de calamidade de grandes

\footnotetext{
3 “Art.136. O Presidente da República pode, ouvidos o Conselho da República e o Conselho de Defesa Nacional, decretar estado de defesa para preservar ou prontamente restabelecer, em locais restritos e determinados, a ordem pública ou a paz social ameaçadas por grave e iminente instabilidade institucional ou atingidas por calamidades de grandes proporções na natureza [...]". VADE Mecum, op. cit., p. 47.
} 
proporções na natureza que atinja a mesma ordem pública ou a paz social (pressupostos de fundo) (SILVA, 2005, p. 764).

O Estado de defesa será instaurado por decreto presidencial, em que se estabelecerá o prazo de duração (que não poderá ser superior a trinta dias, havendo a possibilidade de apenas uma prorrogação, por igual período, se persistirem as razões que justificaram a decretação), as áreas abrangidas e indicará as medidas coercitivas a serem tomadas.

Antes de decretá-lo, o Presidente da República ouvirá o Conselho da República e 0 Conselho da Defesa Nacional (arts.90, $1^{4} ; 91, \S 10, \|^{5}$ e 136), cujas opiniões não vincularão a decisão do Presidente.

Após a decretação, haverá apreciação da medida pelo Congresso Nacional dentro de vinte e quatro horas. Se rejeitada a decretação, seus efeitos são suspensos, sem prejuízo da responsabilidade pelos atos ilícitos até então praticados pelos seus realizadores (arts. 136,\$70 ${ }^{6}$ e 141, CF $^{7}$ ) (SILVA, 2005, p. 764).

0 controle congressual poderá ser concomitante ou sucessivo. Caberá à Mesa do Congresso Nacional (art.57, §5으, CF) ${ }^{8}$ designar comissão composta por cinco membros para acompanhar e fiscalizar a execução de medidas referentes ao Estado de defesa ou então incidirá após o término da vigência do Estado de defesa e à cessação dos seus efeitos (art. 141, parágrafo único, CF) ${ }^{9}$.

\footnotetext{
4 “Art.90. Compete ao Conselho da República pronunciar-se sobre:

I - Intervenção federal, estado de defesa e estado de sítio;

[...]". Ibidem, p.34

5 “Art.91. [...]

$\S 1$ - Compete ao Conselho de Defesa Nacional:

[...]

II - opinar sobre a decretação do estado de defesa, do estado de sítio e da intervenção federal;

[...]". Ibidem, p. 35.

6 "Art.136. [...]

$\S 7^{\circ}$. Rejeitado o decreto, cessa imediatamente o estado de defesa". Ibidem, p. 47.

7“Art.141. Cessado o estado de defesa ou o estado de sítio, cessarão também seus efeitos, sem prejuízo da responsabilidade pelos ilícitos cometidos por seus executores ou agentes [...]". Ibidem, p. 47.

8 "Art.57. [...]§50. A M esa do Congresso Nacional será presidida pelo Presidente do Senado Federal, e os demais cargos serão exercidos, alternadamente, pelos ocupantes de cargos equivalentes na Câmara dos Deputados e no Senado Federal.

[...]". Ibidem, p. 29.

9"Art.141. [...]

Parágrafo Único. Logo que cesse o estado de defesa ou o estado de sítio, as medidas aplicadas em sua vigência serão relatadas pelo Presidente da República, em mensagem ao Congresso Nacional, com
} 
Além do controle político feito pelo Congresso Nacional, o Estado de defesa se submete também ao controle jurisdicional. 0 rigor do controle se justifica pela circunstância de implicar a relativização da autonomia estadual e a limitação temporária de direitos fundamentais (SILVA, 2005, pp. 764-765).

A terceira hipótese é o Estado de sítio que corresponde à suspensão temporária e localizada de garantias constitucionais, em que o Presidente da República deverá obrigatoriamente solicitar autorização da maioria absoluta dos membros da Câmara dos Deputados e do Senado Federal para decretá-lo (M ORAES, 2005, p. 787).

O Estado de sítio objetiva preservar ou restaurar a normalidade constitucional, perturbada por comoção grave de repercussão nacional ou por situação beligerante com Estado estrangeiro e é mais grave que o Estado de defesa, por isso suas restrições aos direitos fundamentais são ainda maiores.

As condições para a decretação do Estado de sítio estão descritas no art.137 da CF, 0 qual no seu inciso I menciona duas situações ${ }^{10}$. A primeira situação é quando se tenha grave comoção de repercussão nacional (enquanto no Estado de defesa a instabilidade se atém a locais restritos e determinados, no Estado de sítio a crise é generalizada), a segunda é quando ocorrem fatos que comprovem a ineficácia das medidas adotadas durante 0 Estado de defesa (aqui a instabilidade legitimadora da decretação do Estado de defesa pode se mostrar mais grave, exigindo medidas adicionais, instaurando-se o Estado de sítio).

Constatadas as situações acima, o Presidente da República decretará o Estado de sítio, tendo antes ouvido os Conselhos da República e de Defesa Nacional (cujos pronunciamentos não vinculam a decisão do ente competente - art.137, CF) e solicitado a autorização do Congresso Nacional. Apenas em caso de crise efetivamente muito grave, que exija medidas inadiáveis, justifica-se a atuação imediata do Presidente da República.

especificação e justificação das providências adotadas, com relação nominal dos atingidos, e indicação das restrições aplicadas". Ibidem, pp. 47-48.

10 "Art.137. O Presidente da República pode, ouvidos o Conselho da República e o Conselho de Defesa Nacional, solicitar ao Congresso Nacional autorização para decretar estado de sítio nos casos de:

I - comoção grave de repercussão nacional ou ocorrência de fatos que comprovem a ineficácia de medida tomada durante 0 estado de defesa; [...]". Ibidem, p.47. 
O decreto presidencial indicará a duração, as medidas necessárias à execução do Estado de sítio e as garantias constitucionais que ficarão suspensas, além de designar o executor das medidas e estabelecer as áreas abrangidas (art.138, CF). ${ }^{11}$

Assim como o Estado de defesa, o Estado de sítio está sujeito ao controle político e jurisdicional. 0 controle político se exercita por meio do Congresso Nacional que deve aprovar previamente a decretação da medida, já que o Estado de sítio é mais gravoso que o Estado de defesa, devendo ter um controle ainda mais intenso.

Além do controle congressual prévio há o controle concomitante (pois cabe à M esa do Congresso designar cinco membros para fiscalizar a execução das medidas - art. 140, $\mathrm{CF}^{12}$ ) e o sucessivo (pois cessados os efeitos do Estado de sítio, as providências serão relatadas pelo Presidente ao Congresso Nacional - art. 141, parágrafo único, CF).

O controle jurisdicional, por sua vez, deve garantir a observância da legalidade excepcional, momento em que o Estado de sítio suspende diversas franquias democráticas.

Ressalte-se que tanto o Estado de defesa quanto o Estado de sítio integram 0 sistema constitucional de crises, em que se pretende defender o Estado e os compromissos e instituições democráticos, sendo estes os tipos de Estados de exceção vigentes na atualidade (SILVA, 2005, p. 763).

Muito embora a intervenção seja caso excepcional de atuação das Forças Armadas, não é considerada Estado de exceção.

As outras três hipóteses de atuação das Forças Armadas na Segurança Pública diferem significativamente das já abordadas, pois não interferem no exercício de direitos fundamentais nem na autonomia dos Estados (BARROSO, 2008).

Deste modo, a quarta hipótese se refere às ações de segurança nas quais haja predominância do interesse nacional, como é o caso de eventos oficiais em que estejam presentes representantes de outras nações. É regulada pelo art.50, parágrafo único do Decreto $3.897 / 01^{13}$, segundo o qual o emprego das Forças Armadas na garantia da lei e da

11 "Art.138. 0 decreto do estado de sítio indicará sua duração, as normas necessárias a sua execução e as garantias constitucionais que ficarão suspensas, e, depois de publicado, o Presidente da República designará 0 executor das medidas específicas e as áreas abrangidas [...]". Ibidem, p. 47.

12 “Art.140. A M esa do Congresso Nacional, ouvidos os líderes partidários, designará Comissão composta de cinco de seus membros para acompanhar e fiscalizar a execução das medidas referentes ao estado de defesa e ao estado de sítio". Ibidem, p. 47.

13 "Art.5․ 0 emprego das Forças Armadas na garantia da lei e da ordem, que deverá ser episódico, em área previamente definida e ter a menor duração possível, abrange, ademais da hipótese objeto dos arts. 30 e 4으, 
ordem alberga os casos em que se presuma possível a perturbação da ordem, como as relativas a eventos oficiais ou públicos, particularmente os que contem com a participação de Chefe de Estado, ou de Governo estrangeiro, e à realização de pleitos eleitorais, quando solicitado. Nesses casos, "as Forças Armadas atuarão em articulação com as autoridades locais" (art.5ㅇ, parágrafo único do Decreto 3.897/01) (BARROSO, 2008).

A quinta hipótese, atinente às ações de segurança por solicitação do Governo do Estado, é a que mais tem relevância para o tema discorrido.

Regulada pela Lei Complementar 97/99, com redação modificada pela Lei Complementar 117/2004, que possui previsão no art.142, §1ํ ${ }^{14}$ da CF, permite ações de segurança por parte das Forças Armadas sem a decretação das medidas de exceção já examinadas (intervenção federal, Estado de defesa e Estado de sítio), o que facilita sua execução (BARROSO, 2008).

A Lei Complementar que regula o assunto teve como substrato o projeto de lei do Deputado Antônio Carlos Biscaia (PT-RJ), cuja finalidade era atender o reclamo de toda a sociedade brasileira e de diversos parlamentares quanto à necessidade de intervenção das Forças Armadas quando os índices de violência e de criminalidade ficassem insustentáveis (BARROSO, 2008).

Nesse âmago, o emprego das Forças Armadas poderá ocorrer na garantia da lei e da ordem, após esgotados os instrumentos destinados à preservação da ordem pública e da incolumidade das pessoas e do patrimônio relacionados no art.144 da CF (art. 15, §2이 da Lei Complementar 97/99). Consideram-se esgotados os instrumentos quando isso for formalmente reconhecido pelo chefe do Poder Executivo estadual (BARROSO, 2008).

Note-se que o chefe do Poder Executivo não precisa esgotar os meios elencados pelo art.144 da CF, bastando a constatação prévia de que não serão suficientes para alcançar o resultado esperado; assim, os meios devem estar indisponíveis ou serem inexistentes ou

outras em que se presuma ser possível a perturbação da ordem, tais como as relativas a eventos oficiais ou públicos, particularmente os que contem com a participação de Chefe de Estado, ou de Governo, estrangeiro, e à realização de pleitos el eitorais, nesse caso quando solicitado. Parágrafo único. Nas situações de que trata este artigo, as Forças Armadas atuarão em articulação com as autoridades locais, adotando-se, inclusive, o procedimento previsto no art. 40." BRASIL. Decreto no 3.897, de 24 de agosto 2001: fixa as diretrizes para o emprego das forças armadas na garantia da lei e da ordem, e dá outras providências. 2001. Disponível em: ঝhttp://direitomilitar.net/legislacao/DEC3897.htm>. Acesso em: 25 maio 2009.

14 “Art.142. [...] $\S 1$. Lei complementar estabelecerá as normas gerais a serem adotadas na organização, no preparo e no emprego das Forças Armadas [...]." VADE M ecum, op. cit., p. 48. 
insuficientes para que haja a convocação das Forças Armadas (art.15, §3ํ, da Lei Complementar 97/99).

Muito embora inexista pronunciamento do STF a respeito do assunto, a hipótese "in examine" se harmoniza com o texto constitucional, já que a atuação das Forças Armadas nesse caso depende de pedido formulado pelo Governador do Estado, sendo o Estadomembro que requer a ação militar e não a União que a determina unilateralmente, a exemplo do Estado de defesa e Estado de sítio (BARROSO, 2008).

Com efeito, a Lei Complementar 97/99 cria um instituto inserido no modelo de federalismo que predomina na Constituição de 1988 - o federalismo cooperativo. Além de compatível com o modelo cooperativo de federação tem como pilar o princípio da subsidiariedade, segundo o qual o Governo da União é desincumbido de realizar tarefas que os governos estaduais tenham plenas condições de desempenhar (BARROSO, 2008).

Além disso, nessa hipótese, o emprego das Forças Armadas será episódico, em área determinada previamente e tempo limitado, conforme redação do art.15, §4으 da Lei Complementar 97/99. Para isso, necessária a demanda de acordo detalhado entre Governo Estadual e Federal, que pode ser celebrado por meio de convênio (mecanismo típico do federalismo cooperativo previsto no art.241 da CF).

Os convênios são instrumentos que possibilitam a associação entre o Poder Público e outras entidades (de cunho privado ou público), no intuito de mútua colaboração. No caso específico das Forças Armadas, a reciprocidade se dá com tropas, grupamentos, armamentos etc (BARROSO, 2008).

Originalmente, a cooperação se restringia às matérias do art.23 da $\mathrm{CF}^{15}$, compreendendo as competências comuns dos entes federados. Contudo, com a Emenda

\footnotetext{
15 “Art.23. É competência comum da União, dos Estados, do Distrito Federal e dos M unicípios:

I - zelar pela guarda da Constituição, das leis e das instituições democráticas e conservar o patrimônio público;

I - cuidar da saúde e assistência pública, da proteção e garantia das pessoas portadoras de deficiência;

III - proteger os do cumentos, as obras e outros bens de valor histórico, artístico e cultural, os monumentos, as paisagens naturais notáveis e os sítios arqueológicos;

IV - impedir a evasão, a destruição e a descaracterização de obras de arte e de outros bens de valor histórico, artístico ou cultural;

$V$ - proporcionar os meios de acesso à cultura, à educação e à ciência;

VI - proteger o meio ambiente e combater a poluição em qualquer de suas formas;

VII - preservar as florestas, a fauna e a flora;

VIII - fomentar a produção agropecuária e organizar o abastecimento alimentar;
} 
Constitucional 19/98, que alterou o art.241, a possibilidade de cooperação entre os entes federativos foi estendida, não havendo mais especificidade quanto ao tipo de atividade-fim do ajuste, o que permite sua aplicabilidade no que tange a Segurança Pública, embora a matéria não seja agasalhada pelo art.23 da CF.

Apesar de ser uma alternativa a ser utilizada para a atuação das Forças Armadas na Segurança Pública dos Estados-membros, os convênios não tem sido uma prática muito difundida. As Forças Armadas só tem executado ações de segurança na modalidade analisada por períodos muito curtos de tempo. Em geral isso tem ocorrido em casos de greve da Polícia Militar, como foi em Tocantins, Alagoas, Minas Gerais, Paraíba, Pernambuco. Entretanto, para participações mais duradouras, o convênio seria útil para detalhar o modo de transferência de competências, os locais de ocorrência da ação militar e as responsabilidades atribuídas a cada órgão (BARROSO, 2008).

A sexta e última hipótese a ser abordada, é sobre a utilização das Forças Armadas na realização de diligências determinadas em inquérito policial militar, não se relacionando às ações de policiamento ostensivo, mas sim investigatório. Disso se extrai que as Forças Armadas podem exercer tanto um papel ostensivo quanto investigatório, atuando como polícia judiciária. Isso ocorre quando se trata de crime militar e em cumprimento de decisões tomadas pela Justiça M ilitar.

A hipótese em discussão também se insere no quadro de normalidade constitucional, ou seja, não precisa estar em Estado de exceção, pois não relativiza a autonomia estadual nem limita a garantia dos direitos fundamentais.

Segundo art. $8^{\circ}$, b, do Código de Processo Penal Militar (CPPM $)^{16}$, compete à Polícia Judiciária Militar a realização de diligências determinadas pela Justiça Militar, órgão incumbido do julgamento dos crimes militares.

IX - promover programas de construção de moradias e a melhoria das condições habitacionais e de saneamento básico;

$\mathrm{X}$ - combater as causas de pobreza e os fatores de marginalização, promovendo a integração social dos setores desfavorecidos;

$\mathrm{XI}$ - registrar, acompanhar e fiscalizar as concessões de direitos de pesquisa e exploração de recursos hídricos e minerais em seus territórios;

XII - estabelecer e implantar política de educação para a segurança do trânsito.

Parágrafo Único. Leis complementares fixarão normas para a cooperação entre a União e os Estados, 0 Distrito Federal e os M unicípios, tendo em vista o equilíbrio do desenvolvimento e do bem-estar em âmbito nacional." Ibidem, p.17.

16 “Art. 8‥ Compete à polícia judiciária militar: [...] 
A Polícia Judiciária Militar é exercida pelos militares e é relacionada à atividade de investigação.

A atuação das Forças Armadas se concentra principalmente nas buscas e apreensões, após a instauração do inquérito policial militar. As buscas são classificadas pelo CPPM nos artigos 172 e 181 em: a) domiciliar - realizada dentro das casas; b) pessoal procura nas vestes, malas e objetos (BARROSO, 2008).

Se for necessária a emissão de mandado de busca para autorizar a diligência, este deve ser o mais específico possível e atender a todos os requisitos, pois além de inadmissível é inconstitucional a emissão de mandados genéricos, posto que propiciam a possibilidade de excessos e abusos.

A realização de diligências pelas Forças Armadas para apreender, por exemplo, armamento militar furtado é perfeitamente compatível com a $\mathrm{CF} / 88$, porém a normativa constitucional não fornece fundamento para a ocupação de bairros inteiros, sob 0 argumento de diligência de busca e apreensão, o que é uma afronta à constituição. A atuação reiterada das Forças Armadas na Segurança Pública dos Estados-membros é perigosa e pode trazer drásticas conseqüências.

\section{Das conseqüências da atuação reiterada das forças armadas na segurança pública dos estados-membros}

A problemática que hoje se instaura se relaciona com a adoção pela sociedade de uma concepção de confronto e truculência da Segurança Pública.

Muito embora o texto constitucional seja claro ao dispor que a Segurança Pública é um dever do Estado e direito dos cidadãos, em que as políticas de segurança compõem um serviço a ser prestado à comunidade, de modo que o cidadão seja o destinatário do serviço e não seu inimigo - em que o meio correto de atuação é aquela precedida de investigação criminal, sem a truculência policial - a ideologia atual da sociedade é a de que a Segurança

b) prestar aos órgãos e juízes da Justiça Militar e aos membros do Ministério Público as informações necessárias à instrução e julgamento dos processos, bem como realizar as diligências que por eles forem requisitadas; [...]." BRASIL. Código de Processo Penal Militar - CPPM - DL-001.002-1969. Disponível em: «ttp://www.dji.com.br/decretos_leis/1969-001002-cppm/cppm__0007a0008.htm\#Art.\%208\%C2\%BA>. Acesso em: 5 maio 2009. 
Pública deve ser entendida como uma política de embate, em que o Estado tem o dever de enfrentar criminosos, de modo a ocupar áreas em que o crime predomina.

Essa mentalidade traduz a concepção militarizada da Segurança Pública, em que o traficante é considerado inimigo interno. Esta é a postura adotada pelos governos atuais, principalmente pelo governo do Rio de Janeiro no combate ao tráfico nos morros cariocas. Tão evidente é a visão da segurança como uma política de confronto para este Estado, que o próprio governador do Rio, Sérgio Cabral, demonstrou otimismo com a chegada das tropas, e disse esperar que as Forças Armadas continuem atuando na cidade mesmo após as eleições:

- Eu espero que tenha êxito essas forças federais, que elas possam contribuir para o processo das eleições e, quem sabe, até nos entusiasme e continuem aqui nos ajudando a combater a violência (MASCARENHAS; DURAN, 2008). (grifo nosso)

Da militarização da polícia (órgão da Segurança Pública) destaca-se um tipo de treinamento particular da tropa. Desta forma, utilizam-se as mesmas técnicas para a formação de um soldado no treinamento do policial - técnicas de guerra, que é exatamente o que se presencia hoje em dia.

Nesse âmbito, as estratégias militares de ocupação e combate predominam sobre a investigação e a inteligência policial. Ao invés de se investigar para obter resultados específicos, as autoridades engajam em grandes operações de choque e ocupação. A truculência dos aparelhos de Estado é convertida em procedimento normal, nada obstante os diversos efeitos colaterais que provoca, como o expressivo número de mortes durante os confrontos, inclusive mortes de inocentes e o que era para ser exceção, quanto a atuação das Forças Armadas, se torna regra.

Numa visão constitucional da temática em discussão, a utilização das Forças Armadas é contrária às ações de Segurança Pública, uma vez que esta concepção se harmoniza com o Estado democrático de direito e com a normalidade constitucional. Os que defendem essa dogmática entendem que as FAs não estão preparadas para prestar esse serviço público, uma vez que suas ações são focadas a outros fins. Nesse diapasão, conceber o serviço público a ser prestado aos cidadãos significa enfatizar na formação dos policiais (não apenas as técnicas de enfrentamento em conflito bélico); valorizar temas como direitos 
humanos, relações públicas e participação da comunidade; e preparar para a investigação e para a inteligência policial.

Todavia, mesmo havendo certa apatia quanto à interferência das Forças Armadas na Segurança Pública não há como evitar que em momentos de necessidade, em que a ordem pública esteja efetivamente em risco, tal fato tenha ocorrência, sendo de extrema exatidão a atuação das Forças Armadas na Segurança Pública nesse caso.

De acordo com a visão constitucional, a atuação das Forças Armadas na Segurança Pública não é rechaçada, mas restringe-se a momentos excepcionais, não devendo ser algo recorrente.

Como enfatizado, embora as Forças Armadas não sejam expressamente amparadas pelo rol dos órgãos de Segurança Pública do art.144 da CF, sua participação na segurança possui fundamento constitucional no art.142, quando se refere à garantia dos poderes constitucionais, da lei e da ordem.

A polêmica maior que paira sobre 0 tema diz respeito, principalmente, ao policiamento ostensivo e ao de choque no âmbito interno dos Estados - atividades estas atribuídas pela CF às Polícias Militares estaduais, por esse motivo é que as Forças Armadas atuam de forma delimitada em hipóteses específicas, como já discorrido.

As hipóteses de atuação das Forças Armadas na Segurança Pública têm previsão constitucional expressa e disciplina analítica, pois são associadas a situações que interferem potencialmente no exercício de direitos fundamentais e na autonomia federativa. Por esse motivo, o eventual emprego das Forças Armadas nesses contextos estará sujeito a limites e controles políticos especiais, que incluem restrição de tempo, demarcação de área geográfica e fiscalização parlamentar rígida, como já descritos.

Contudo, não é uma visão constitucional que os governantes de alguns Estados manifestam, pelo contrário, acreditam numa política de combate, em que se instaure um confronto armado dentro do país, nos moldes do Exército, como se estivessem lidando com um inimigo externo tendo o objetivo de aniquilá-lo.

0 problema é que com a adoção dessa política de Segurança Pública há grandes possibilidades de se instaurar uma guerra civil interna, o que pode gerar inúmeros percalços, dentre eles o Estado de caos e o desaparecimento do Estado Social Democrático de Direito e 
do equilíbrio do pacto federativo, já que o fundamento da mínima intervenção é justamente a preservação destes institutos.

0 que se verifica no momento atual é que devido a militarização da Polícia Militar (encarregada do policiamento ostensivo dos Estados-membros) e a má preparação e remuneração dos policiais, o índice de criminalidade vem aumentando assustadoramente, de modo que os órgãos da Segurança Pública encarregados de manter a pacificidade e a segurança não dão conta de suas funções e necessitam do apoio direto das Forças Armadas, utilizando como fundamento o desempenho de "ações de segurança por solicitação dos governos dos Estados", para a manutenção da lei e da ordem, amparado na Lei Complementar 97/99 e art.142,\$1ㅇ da Constituição Federal. Contudo, esqueceram-se de que a multiplicidade dos órgãos de defesa dos Estados se deu justamente para haver uma menor intervenção das Forças Armadas na segurança interna dos Estados-membros.

Outro problema é que o emprego de forças militares despreparadas ou malformadas pode trazer sério risco ao exercício da democracia, à liberdade e à vida. Nesse sentido, são preciosos os ensinamentos do professor Paulo Queiroz (2008):

[...]Mais: que se há de esperar de uma polícia e Exército militares senão que atuem militarmente, isto é, para a guerra, com a disposição, as armas e táticas da guerra? Ora, a contradição é evidente: funções não militares (v.g., Segurança Pública) são de todo incompatíveis com instituições militares, que só devem exercer tarefas militares e, eventualmente, devem ser desmilitarizadas ou mesmo extintas. Não há meio termo.

Exemplo vivenciado disso foi o caso do assassinato dos três jovens do Morro da Providência, que iniciou um debate mais profundo sobre a possível atuação das Forças Armadas na Segurança Pública no Brasil.

Quanto a isso, divergem as opiniões. Enquanto o governador do Rio, Sérgio Cabral, insiste veementemente de forma reiterada para que haja ajuda das Forças Armadas na Segurança Pública do Estado, principalmente no que tange ao confronto do narcotráfico, alguns governantes, como o deputado tucano, Otávio Leite do Rio de Janeiro, entendem ser indispensável uma reflexão mais profunda sobre o papel do Exército Brasileiro, em especial em função do trágico episódio do Rio de Janeiro. 
Raul Jungmann, deputado pernambucano, na mesma esteira entende que além de se tratar de uma questão explícita dos direitos humanos, o caso do Morro da Providência levanta uma "questão política".

Para ele a matriz do erro advém da não regulamentação da garantia da lei e da ordem (atribuição subsidiária das Forças Armadas), que é imprescindível por se tratar de instituições nacionais permanentes como o Exército (M ILANI, 2008).

De igual modo, o Ministro da Defesa, Nelson Jobim, defende a criação de um estatuto que regulamente a atuação das Forças Armadas em apoio à Segurança Pública, como por exemplo, em operações contra o tráfico de drogas. De acordo com o ministro, o esboço do projeto de lei que servirá de base para discussões envolvendo governo e sociedade civil deverá estar pronto até agosto de 2009.

Destacou ainda que:

Deseja-se o fim, mas não quer se debater o meio. A sociedade discute muito a participação das tropas em operações internas, mas não debate as regras jurídicas para tais atividades. Alguns setores pretendem o uso das Forças Armadas em operações contra organizações criminosas e o Rio de Janeiro é o maior exemplo disso (LEITÃO, 2009).

Além disso, criticou a atuação das Forças Armadas em funções que substituem às forças estaduais de Segurança Pública: "A intervenção só deve ser feita diante da impossibilidade das forças estatais resolverem o problema. Ela será sempre subsidiária, complementar e auxiliar. Nunca primária" (LEITÃO, 2009).

0 embaixador Rubens Barbosa também tece críticas sobre 0 assunto. Segundo ele, as propostas de atuação das Forças Armadas na Segurança Pública, com operações contra o tráfico de drogas ou intervenção no caso de violência urbana da cidade do Rio de Janeiro provocaram certa relutância das Forças por estas não serem preparadas e não possuírem equipamentos para tais operações. Chamou também a atenção para 0 baixo orçamento repassado para as três Armas, que representa apenas 1,7\% de todo o Produto Interno Bruto (PIB) do país, sendo um dos mais baixos da América do Sul, o que torna notória a necessidade de modernização dos equipamentos e repasse de maiores recursos para que as FAs exerçam adequadamente suas funções. Para ele, isso só será viável quando o país tiver 
um M inistro da Defesa Civil que defenda a hierarquia, interesses e princípios militares "com políticas voltadas para a recuperação da capacidade operacional". ${ }^{17}$

Do exposto, extrai-se que as conseqüências da reiterada atuação das Forças Armadas na Segurança Pública dos Estados-membros são: a) infração à norma constitucional; b) enfraquecimento do Estado democrático de direito; c) desarmonia dos três poderes; d) desequilíbrio do pacto federativo; e) instauração do Estado de caos; f) esfacelamento dos direitos fundamentais, como direito à vida, à propriedade e outros; g) diminuição da atuação dos órgãos da Segurança Pública encarregados de prover a segurança dos estados-membros.

Diante das conseqüências calamitosas acima expostas, as propostas para a solução dos problemas se encontram: a) na adoção de uma política nacional de Segurança Pública que tenha os cidadãos como seus destinatários e não como seus inimigos, que seja constituída em conjunto pela sociedade, pelos órgãos de Segurança Pública, ONGs etc.; b) na desmilitarização e estruturação correta da Polícia M ilitar; c) no maior investimento da União na Segurança Pública dos Estados-membros e Municípios; d) na atuação conjunta entre Estados e Municípios na Segurança-Pública, por meio de convênios (a partir da aprovação do projeto de lei que tramita no Congresso Nacional, que prevê a atuação ostensiva das Guardas M unicipais).

O primeiro passo já foi dado, as etapas municipal e estadual da $1^{a}$ Conseg (Conferência Nacional de Segurança Pública) já se realizaram.

\section{Conclusão}

A elaboração deste estudo permitiu o esclarecimento de que a atuação das Forças Armadas na Segurança Pública dos Estados-membros se dá somente em caráter excepcional, posto que a regra é a da não-intervenção. Deste modo, deve obediência aos ditames do art.142 da CF.

Com o propósito de garantir a lei e a ordem (art.142, CF), têm-se hipóteses restritas de atuação das Forças Armadas na Segurança Pública dos Estados-membros. Dentre elas, a de maior relevância é a que trata do policiamento ostensivo e de choque, por solicitação do

${ }^{17}$ OBSERVATÓRIO CONO SUR DE DEFENSA Y FUERZAS ARMADAS. Informe Brasil no293: semana del 23 al 29/06/07. Disponível em: বhttp://www.cee-chile.org/resumen/brasi/bra251-300/sembra293.htm>. Acesso em: 22 maio 2009. 
governador de Estado-membro, o que deve ocorrer, tão só, após esgotados os instrumentos destinados à preservação da ordem pública e da incolumidade das pessoas e do patrimônio, fato que deve ser reconhecido pelo chefe do Poder Executivo estadual.

Oposto a isso, a realidade vivida demonstra o freqüente emprego das Forças Armadas na Segurança Pública dos Estados-membros. Em verdade, tal atuação deveria ocorrer em momentos de extrema necessidade, pois a reiterada intervenção desencadeia situações caóticas, como o caso do M orro da Providência.

Esse e outros casos decorrem da concepção de segurança adotada pela sociedade, com visão de embate e confronto; pela ausência de uma política de segurança; pela falta de infra-estrutura das polícias, que não desempenham corretamente seus papéis, em virtude da falta de investimento e preparação; e pelo militarismo da Polícia Militar herdado do Exército.

Deste modo, para que haja efetividade à garantia do direito à segurança e para que os ditames legais sejam estritamente cumpridos, é mais do que necessário que se estabeleça uma política de nacional de Segurança Pública, em que toda a sociedade, poderes Executivo, Legislativo e Judiciário, bem como todos os órgãos e componentes da estrutura de Segurança Pública dos Estados-membros participem de sua elaboração, aprovação e acompanhamento.

\section{Referências}

BARROSO, Luís Roberto. Segurança pública: atuação das forças armadas tem de ser excepcional. Consultor Jurídico, 26 jun. 2008. Disponível em:

বttp://www.conjur.com.br/static/text/67573,1>. Acesso em: 10 maio 2008.

BRASIL. Código de Processo Penal Militar - CPPM - DL-001.002-1969. Disponível em: বhttp://www.dji.com.br/decretos_leis/1969-001002-

cppm/cppm__0007a0008.htm\#Art.\%208\%C2\%BA>. Acesso em: 5 maio 2009.

BRASIL. Decreto $\mathrm{n} 0$ 3.897, de 24 de agosto 2001: fixa as diretrizes para o emprego das forças armadas na garantia da lei e da ordem, e dá outras providências. 2001. Disponível em: বhttp://direitomilitar.net/legislacao/DEC3897.htm>. Acesso em: 25 maio 2009.

BRASIL. Estado Maior das Forças Armadas. Glossário das Forças Armadas: aprovado pela Portaria Normativa no 196/EM D/M D, de 22 de fevereiro de 2007. 4. ed. Brasília, 2007. 
LEITÃO, Thais. Jobim defende estatuto para definir atuação das forças armadas na segurança pública. Agência Brasil, 18 maio 2009. Disponível em:

४http://www .agenciabrasil.gov.br/noticias/2009/05/18/materia.2009-05-

18.9364523509/view >. Acesso em: 22 maio 2009.

M ASCARENHAS, Gabriel; DURAN, Sérgio. Eleições 2008: Operação Guanabara: Forças Armadas começam a ocupar áreas do Rio no combate aos currais eleitorais. 0 Globo, 11 set. 2008. Disponível em:

४http://oglobo.globo.com/pais/eleicoes2008/mat/2008/09/11/operacao_guanabara_forcas _armadas_comecam_ocupar_areas_do_rio_no_combate_aos_currais_eleitorais$\overline{5} 4817877 \overline{3}$. asp $>$. Acesso em: 22 maio 2009 .

MILANI Aloísio. Debate sobre atuação dos militares na segurança pública. 20 jun. 2008. ४ttp://aloisiomilani.wordpress.com/2008/06/20/ debate-sobre-atuacao-dos-militares-naseguranca-publica/>. Acesso em: 22 maio 2009.

M IRANDA, Pontes de. Comentários à constituição de 1967 com a emenda n.1 de 1969. São Paulo: Revista dos Tribunais, 1970.

M ORAES, Alexandre de. Direito constitucional. 23 ed. São Paulo: Atlas, 2008.

NOBRE, Thiago Lacerda. A falência da segurança pública nos estados e a atuação das forças armadas na garantia da lei e da ordem. abr. 2007. Jus Navigandi.

বhttp://jus2.uol.com.br/doutrina/texto.asp?id=9794>. Acesso em: 22 maio 2009.

OBSERVATÓRIO CONO SUR DE DEFENSA Y FUERZAS ARM ADAS. Informe Brasil n293:

semana del 23 al 29/06/07. Disponível em: «ttp://www.cee-

chile.org/resumen/brasi/bra251-300/sembra293.htm>. Acesso em: 22 maio 2009.

SILVA, José Afonso da. Curso de direito constitucional positivo. 24 ed. São Paulo: Malheiros, 2005.

QUEIROZ, Paulo. Por que a polícia continuará matando pessoas inocentes? Revista Jus Vigilantibus, 11 jul. 2008. «ttp://jusvi.com/colunas/34593>. Acesso em: 11 jul 2008.

SILVA, José Afonso da. Curso de direito constitucional positivo. 24. ed. São Paulo: Malheiros, 2005.

VADE M ecum. 5 ed. São Paulo: Saraiva, 2008. 